Seung-Jae Hyun ${ }^{1}$,

Byoung Hun Lee ${ }^{1}$, Jong-Hwa Park ${ }^{2}$, Ki-Jeong Kim", Tae-Ahn Jahng ${ }^{1}$, Hyun-Jib Kim ${ }^{1}$

${ }^{1}$ Department of Neurosurgery, Spine Center, Seoul National University Bundang Hospital, Seoul National University College of Medicine, Seongnam, ${ }^{2}$ Department of Neurosurgery, Kangdong Sacred Heart Hospital of Hallym University Medical Center, Seoul, Korea

\section{Corresponding Author:}

Byoung Hun Lee

Department of Neurosurgery, Spine Center, Seoul National University Bundang Hospital, Seoul National University College of Medicine, 82 Gumi-ro 173beon-gil, Bundang-gu, Seongnam 13620, Korea

Tel: +82-31-787-7164

Fax: +82-31-787-4097

E-mail: neurospine@snubh.org

Received: December 13, 2017 Revised: December 24, 2017

Accepted: December 26, 2017

Copyright (c) 2017 by The Korean Spinal Neurosurgery Society

This is an open access article distributed under the terms of the Creative Commons Attribution Non-Commercial License (http://creativecommons.org/licenses/bync/4.0/) which permits unrestricted noncommercial use, distribution, and reproduction in any medium, provided the original work is properly cited.

\title{
Proximal Junctional Kyphosis and Proximal Junctional Failure Following Adult Spinal Deformity Surgery
}

The purpose of this review is the current understanding of proximal junctional kyphosis (PJK) and proximal junctional failure (PJF) following adult spinal deformity (ASD) surgery. We carried out a systematic search of PubMed for literatures published up to September 2017 with "proximal junctional kyphosis," "proximal junctional failure," and "adult spinal deformity" as search terms. A total of 98 literatures were searched. The 37 articles were included in this review. PJK is multifactorial in origin and likely results from variable risk factors. PJF is a progressive form of the PJK spectrum including bony fracture, subluxation between UIV and UIV+1, failure of fixation, neurological deficit, which may require revision surgery for proximal extension of fusion. Soft tissue protections, adequate selection of the UIV, prophylactic rib fixation, hybrid instrumentation such as hooks, vertebral cement augmentation at UIV and UIV+1, adequate selection material of rods and age-appropriate spinopelvic alignment goals are strategies to minimize PJK and PJF. The ability to perform aggressive global realignment of spinal deformities has also led to the discovery of new complications such as the PJK and PJF. Continuous research on PJK and PJF should be proceeded in order to comprehend the pathophysiology of these complications.

Key Words: Proximal junctional kyphosis, Proximal junctional failure, Adult spinal deformity, Complications

\section{INTRODUCTION}

Proximal junctional kyphosis (PJK) and proximal junctional failure (PJF) are recognized complications after long instrumented posterior fusion in adult spinal deformity (ASD) surgery ${ }^{22,34,51)}$. $\mathrm{PJK}$ is a radiologic phenomenon of adjacent segment pathology and ongoing adjacent segmental problems at the transition between fused and mobile motion segments, ${ }^{4,22,39)}$. PJK has a spectrum of disease severities from no clinical symptom to causing clinical symptom which may require revision surgery. PJF is a progressive process in the spectrum of PJK with structural failures such as vertebral body fracture and/or posterior ligament complex, and vertebral subluxation. PJF may present higher morbidities including pain, neurologic deficit, and revision surgery ${ }^{16,38,48)}$. This study was designed to provide comprehensive background materials for PJK and PJF after ASD surgery from thorough review of current literatures.

\section{MATERIALS AND METHODS}

We carried out a systematic search of PubMed for literatures published up to September 2017 with "proximal junctional kyphosis," "proximal junctional failure," and "adult spinal deformity" as search terms. A total of 98 literatures were searched. Case reports and articles that did not focus on PJK and PJF were excluded. Finally, the 37 articles were included in this review.

\section{DEFINITION OF PROXIMAL JUNCTIONAL KYPHOSIS}

There is no confirmative consent on the definition of PJK at present. As suggested by the terminology, PJK was defined as a kyphotic deformity in the spinal motion segments immediately cephalad to the instrumented segments ${ }^{15)}$. PJK was first defined in the literature by Bridwell and colleagues as a proximal junctional sagittal Cobb angle between the lower endplate of uppermost instrumented vertebra (UIV) and the upper endplate of 2 supra-adjacent vertebra $\geq 10^{\circ}$ or at least $10^{\circ}$ greater than the preoperative measurement ${ }^{7}$.

Another researcher defined PJK as a proximal junctional sagittal Cobb angle between the lower endplate of UIV and the upper endplate of one supra-adjacent vertebra $\geq 15^{\circ 15)}$. They suggested that the arbitrary selection of $5^{\circ}$ or $10^{\circ}$ does not correlate with clinical symptoms 
or adjacent level disease. Their criteria $\geq 15^{\circ}$ was based on the standard deviation of all postoperative patients in their study and the assumption that normal is within 2 standard deviations.

Bridwell et at. ${ }^{2)}$ and O'Shaughnessy et al. ${ }^{39)}$ used $20^{\circ}$ between UIV and 2 supra-adjacent vertebra as the cutoff for defining meaningful PJK. They suggested that PJK occurs with fairly high prevalence after adult deformity surgery and $\mathrm{PJK} \geq 20^{\circ}$ does not lead to revision surgery but it can be a meaningful cutoff value for poor outcomes.

Hostin et al. ${ }^{16}$ set a reference angle $15^{\circ}$ between UIV and 2 supra-adjacent vertebra based on the results of a large multicenter and retrospective study. Many authors suggested that varied angulation from 5 to $20^{7,15,16,30,39)}$. To date, the angulation of PJK which at least 10 degrees greater than preoperative measurement is the most repeatedly used definition of PJK in the $\operatorname{articles}^{4,7,12,40)}$.

PJK is not a single disease but a spectrum having various severities of disease. In early time literatures, PJK has not been found to cause significant clinical symptoms or structure failures. In those studies, there are no significant differences between the groups with or without PJK in Scoliosis Research Society-22 scores and clinical symptoms ${ }^{7,18,25,49)}$.

\section{DEFINITION OF PROXIMAL JUNCTIONAL FAILURE}

$\mathrm{PJF}$ is a progressive form of the PJK spectrum including verte-
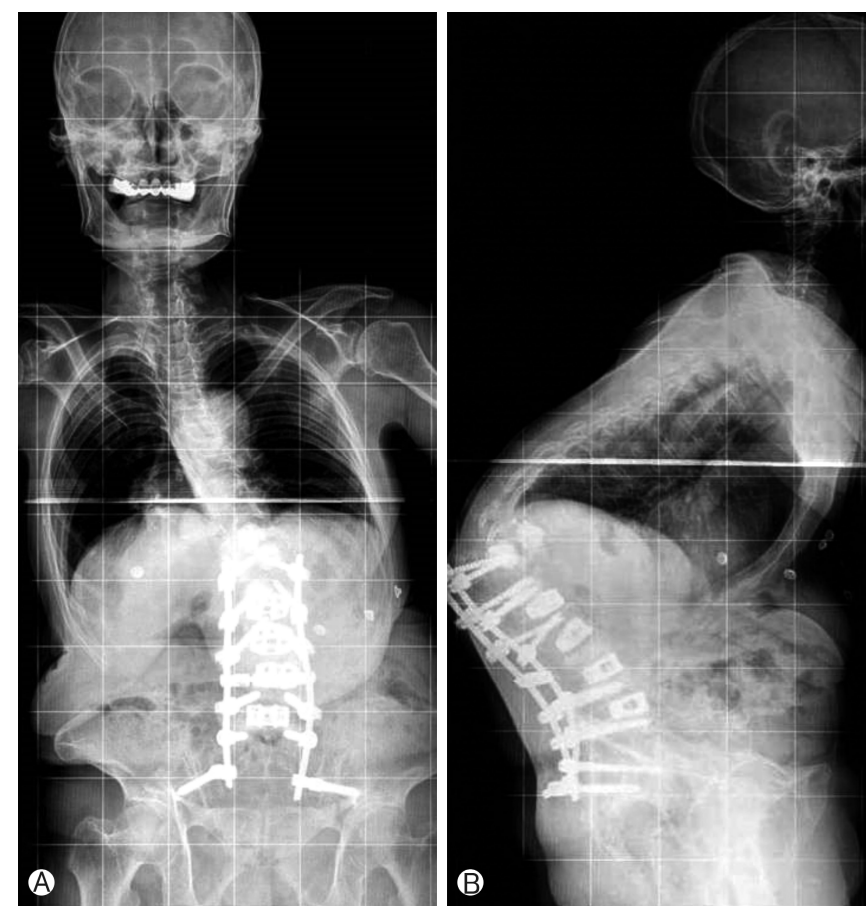

Fig. 1. Antero-posterior (A) and lateral (B) plain radiographs of the patient. The subluxation at the proximal level of uppermost instrumented vertebra caused severe thoracolumbar junction kyphosis and trunk shift to left side. bral fracture of UIV or UIV +1 , subluxation between UIV and $\mathrm{UIV}+1$, failure of fixation, neurological deficit, which may require revision surgery for proximal extension of fusion ${ }^{16,40,44,49)}$. Yagi et al. ${ }^{52)}$ defined PJF as symptomatic PJK requiring any types of surgery. The structural failure that occurs with PJF can present as vertebral body fracture, implant pull-out or breakage, and/or disruption of the posterior osseo-ligamentous complex ${ }^{11,16}$. Patients with PJF have significantly worse clinical symptoms and Oswestry disability index scores ${ }^{24,51)}$. Other terms used to describe PJF have included "topping off syndrome," "proximal junctional fracture," and "proximal junctional acute collapse." These terms highlight the associated structural failure and mechanical instability that distinguish this more severe form of proximal junctional pathologies from $\mathrm{PJK}^{35}$.

A case of catastrophic PJF is shown in Figs. 1 and 2. The subluxation at the proximal level of UIV caused severe thoracolumbar junction kyphosis, trunk shift to left side, disruption of posterior ligament complex, and rod protrusion penetrating the skin. Revision surgery for fusion extension to proximal upper thoracic level was performed (Fig. 3). The patient was well-tolerated without another PJK/PJF.

\section{CLASSIFICATION OF PROXIMAL JUNCTIONAL KYPHOSIS}

There is a lack of a standardized consensus to determine which patients with PJK need and will benefit most from revision surgery. Two separate classification systems have been proposed (Tables 1, 2). Boachie-Adjei and colleagues initially published their PJK classification in 2011 and subsequently revised it in $2014^{49,52)}$. In their series, most failures were of type $2 \mathrm{~N}$ (bony failure without spondylolisthesis) and most cases with neurologic abnormalities were type $2 S$ (bony failure with spondylolisthesis). This classification has merits that it is simple and easy to describe the type and severity of PJK. It provides an objective means for clinicians to communicate the type of $\mathrm{PJK}^{29}$. However, it has

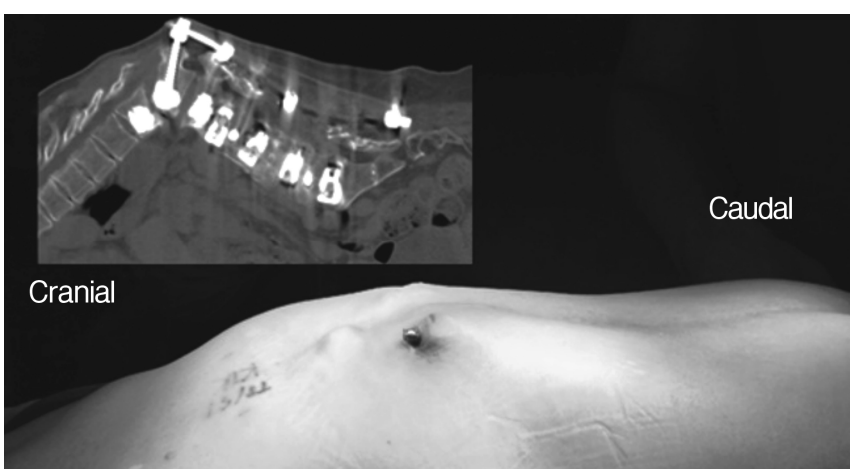

Fig. 2. Sagittal computerized tomography and intraoperative photo of the back of the patient. Severe thoracolumbar junction kyphosis and disruption of posterior ligament complex due to the subluxation at the proximal level of uppermost instrumented vertebra is observed. The proximal portion of rod penetrated the skin. 
drawbacks that it lacks prognostic information and does not guide management. The classification scheme does demonstrate which patients tend to be symptomatic, but it does not provide information regarding the natural course and severity of disease. Thus, according to the classification, the clinicians have difficulty to determine which patients need a treatment including revision surgery. This classification has a limit with respect to patient management.

Hart et al. ${ }^{11)}$ and the International Spine Study Group (ISSG) provided a new PJK classification to guide treatment and provide decision criteria for revision surgery. A proximal junctional kyphosis severity scale that assigns points to 6 different components thought to be important in the evaluation and management of PJK/PJF (Table 2). The 6 components include neurological deficit, focal pain, instrumentation problem, change in kyphosis/ posterior ligament complex integrity, fracture location, and level of UIV. Each component is further categorized and assigned a certain number of points. The points are then summed for a total severity score. The proposed Hart-ISSG PJK severity scale has been shown to have good reliability and repeatability. Its score has been shown to strongly correlate with health-related quality of life outcome scores and indication for revision surgery. The score $\geq 7$ indicates for revision surgery. A prospective study to evaluate its utility is under way.
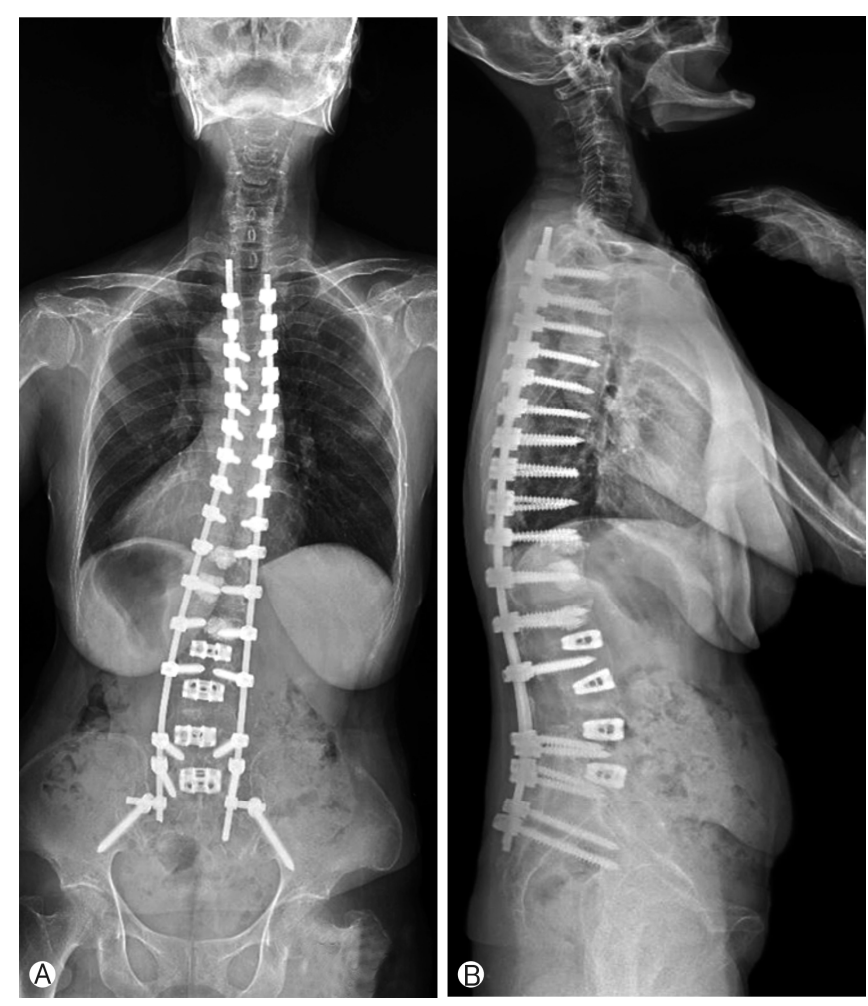

Fig. 3. Postoperative 3 years anteroposterior (A) and lateral (B) plain radiographs of the patient. Revision surgery for fusion extension to upper thoracic level was performed and the patient was well-tolerated without another proximal junctional kyphosis/failure.

\section{INCIDENCE}

Several authors have analyzed the incidence of PJK following ASD surgery. It has been reported from $17 \%$ to $61.7 \% \%^{7,8,18,24,31,33,34,49,51)}$. The incidence has wide range according to the study population and the period of follow-up $(\mathrm{F} / \mathrm{U})$. In the previous study, 42 of

Table 1. Classification of the grades and severity of proximal junctional kyphosis/proximal junctional failure by Boachie-Adjei et al. ${ }^{52)}$

\begin{tabular}{cl}
\hline \hline Type & \multicolumn{1}{c}{ Description } \\
\hline 1 & Disc and ligamentous failure \\
2 & Bone failure \\
3 & Implant/bone interface failure \\
Grade & Proximal junctional increase $10^{\circ}-19^{\circ}$ \\
A & Proximal junctional increase $20^{\circ}-29^{\circ}$ \\
B & Proximal junctional increase $30^{\circ}$ \\
C & \\
Spondylolisthesis & No obvious spondylolisthesis above UIV \\
PJF-N & Spondylolisthesis above UIV \\
PJF-S &
\end{tabular}

Table 2. The Hart-International Spine Study Group proximal junctional kyphosis severity scale

\begin{tabular}{|c|c|c|}
\hline Parameter & Qualifier & $\begin{array}{c}\text { Severity } \\
\text { scale }\end{array}$ \\
\hline \multirow[t]{3}{*}{ Neurologic deficit } & None & 0 \\
\hline & Radicular pain & 2 \\
\hline & Myelopathy/motor deficit & 4 \\
\hline \multirow[t]{3}{*}{ Focal pain } & None & 0 \\
\hline & VAS $\leq 4$ & 1 \\
\hline & VAS $\geq 5$ & 3 \\
\hline \multirow[t]{3}{*}{ Instrumentation problem } & None & 0 \\
\hline & Partial fixation loss & 1 \\
\hline & Prominence & 1 \\
\hline \multirow{4}{*}{$\begin{array}{l}\text { Change in kyphosis/PLC } \\
\text { integrity }\end{array}$} & $\begin{array}{l}\text { Complete fixation loss } \\
0^{\circ}-10^{\circ}\end{array}$ & $\begin{array}{l}2 \\
0\end{array}$ \\
\hline & $10^{\circ}-20^{\circ}$ & 1 \\
\hline & $>20^{\circ}$ & 2 \\
\hline & PLC failure & 2 \\
\hline \multirow[t]{4}{*}{ UIV/UIV +1 fracture } & None & 0 \\
\hline & Compression fracture & 1 \\
\hline & Burst/chance fracture & 2 \\
\hline & Translation & 3 \\
\hline \multirow[t]{2}{*}{ Level of UIV } & Thoracolumbar junction & 0 \\
\hline & Upper thoracic spine & 1 \\
\hline
\end{tabular}

VAS, visual analogue scale; PLC, posterior ligamentous complex; UIV, uppermost instrumented vertebra. 
the 249 patients (17\%) developed PJK during the $\mathrm{F} / \mathrm{U}$ period $^{23)}$. Another researcher investigated an incidence of $20 \%$ for 157 adult idiopathic scoliosis patients during 4.3 years $\mathrm{F} / \mathrm{U}^{49}$. Hyun and Rhim ${ }^{18)}$ reported the incidence of PJK through a multicenter retrospective long-term F/U study. The incidence of PJK was 23\% in patients with fixed sagittal imbalance who underwent pedicle subtraction osteotomy for average 6.1 years F/U. Kim et al. ${ }^{24)}$ investigated an incidence of PJK for 161 ASD patients. They reported 39\% incidence of PJK with 7.8 years F/U. Maruo et al. ${ }^{33)}$ analyzed 90 ASD patients in long fusion to sacrum with an average 2.9-year F/U. They demonstrated $40 \%$ the incidence of PJK. Lee et al. ${ }^{31)}$ reported $61 \%$ of PJK about 47 patients with lumbar degenerative kyphosis surgery during 3.8-year F/U. Whereas, the incidence of PJF was reported between 1.4\% and $35 \%{ }^{16,45,52)}$. Yagi et al. ${ }^{52)}$ introduced that incidence of PJF was $1.4 \%$ in 23 of the 1,668 patients. According to another study, PJF was observed in 60 of the 173 patients $(35 \%)^{45}$.

\section{RISK FACTORS}

Variable risk factors for PJK and PJF have been described in the literatures. It can be categorized into surgical, radiographic, and patient-related risk factors. Surgical risk factors include injury of the posterior soft tissues, combined anterior and posterior approach, fusion to the sacrum/ilium, pedicle screw constructs, rod stiffness, selection of the UIV, the magnitude correction of deformity, and thoracoplasty. Damage of the posterior soft tissues (facet capsule, posterior tension band, etc.) has been suggested as a risk factor for $\mathrm{PJK}^{5,7,9,10,22,24,51,52)}$. The insufficiency of the posterior ligamentous complex by the surgical procedure is not a reversible factor. Previous investigators reasoned that ligamentous failure of the posterior interspinous ligament and paraspinal musculature damage may contribute to increasing of $\mathrm{PJK}^{51)}$. Hyun et al. ${ }^{17)}$ recently reported that preoperative insufficiency muscularity and fatty degeneration in the musculature of thoracolumbar area can cause PJK.

In patients with anteriorposterior spinal fusion, $\mathrm{PJK}$ is three times more likely to occur than patients with posterior fusion ${ }^{22)}$. Fusion to the lower lumbar spine and sacrum also increase the incidence of $\mathrm{PJK}^{34,37,47,49,51)}$. After fusion to lower lumbar spine, trunk attempt to control balance by a change in the lumbar curves. However, the fused lumbar segment interfered with the adjustment and then PJK was increased ${ }^{47}$.

Use of pedicle screw construct is one the risk factors ${ }^{15,25,26,47}$. Helgeson et al. ${ }^{15)}$ has shown that pedicle screw only construct compared with hook and hybrid significantly caused PJK after surgery. The high rigidity of vertebrae with pedicle screw increased adjacent segment kyphosis ${ }^{25,26}$.

The PJK could occur because of increasing the rod stiffness. Han et al. ${ }^{10)}$ explained that when cobalt chrome multiple-rod constructs (CoCr MRCs) and titanium alloy 2-rod constructs ( $\mathrm{Ti}$ TRCs) are used, more PJK occurs in the group using CoCr MRCs (CoCr MRC: $60 \%$ vs. Ti TRC: $26.5 \%)^{10)}$. In another literature, the cobalt chrome $(\mathrm{CoCr})$ rod cause PJK more than titanium alloy (Ti) $\operatorname{rod}(\mathrm{CoCr}: 46 \% \text { vs. Ti: } 18 \%)^{9)}$.
The decision of the UIV may affect the occurrence of $\mathrm{PJK}^{7}$. The UIV at the upper and lower thoracic level have been related with $\mathrm{PJK}^{2,22)}$. The UIV at upper thoracic cause PJK by subluxation and soft tissue failure, whereas UIV at lower thoracic cause PJK secondary to vertebral body fractures ${ }^{16,33)}$. Bridwell et al. ${ }^{2)}$ reported that shorter fused levels (8 vs. 11 levels fused) and a UIV at the lower thoracic than upper thoracic spine were shown to cause the PJK more.

The greater intraoperative curvature correction cause a compensation by the trunk and formation proximal kyphosis ${ }^{47}$. A magnitude correction of deformity is related with the occurrence of $\mathrm{PJK} \mathrm{K}^{21,33,34,51,52)}$. The greater correction of a sagittal vertical axis (SVA) and postoperative lumbar lordosis (LL) may contribute to the risk of $\mathrm{PJK}^{1,33)}$. Mauro et al. ${ }^{33)}$ reported that change in LL more than $30^{\circ}$ was identified as a risk factor.

Wang et al. ${ }^{47}$ pointed out that the thoracoplasty cause injury to anatomically stable structure of the sternum-rib-spine unit. This procedure will make more stress to spine and induce PJK.

Preoperative sagittal imbalance as radiologic factors has been shown to increase $\mathrm{PJK}^{16,26,30,33,40,47,51)}$. Park et al. ${ }^{40)}$ reported that degree of preoperative sagittal imbalance influenced the occurrence of PJK. Mauro et al. ${ }^{33)}$ had investigated spinopelvic parameter and reported that PJK was increased in patients who had higher preoperative thoracic kyphosis, proximal junction angulation, pelvic incidence (PI), and LL. Several authors reasoned that preoperative proximal junctional angle $>5^{\circ}$ increase the risk of junctional kyphosis and $\mathrm{PJF}^{5,11,30)}$.

Older age ( $>55$ years), high body mass index (BMI), and osteoporosis as patient-specific factors for PJK and PJF have been suggested ${ }^{2,21,24)}$. Kim et al. ${ }^{24)}$ explained that degeneration and muscular atrophy by aging expressed more PJK. Low bone density and high BMI are potential risk factors ${ }^{2,38,51)}$. Several studies have reported that osteopenia was common in patients with complications, such as proximal vertebral fracture, subluxation and $\mathrm{PJK}^{16,20,48)}$. Yagi et al. ${ }^{50)}$ reported that low bone mineral density was a risk factor for PJF (T-score <-1.5; odd ratio, 6.4). Bridwell et $\mathrm{al}^{2)}$ reported that BMI was related to the occurrence of PJK.

\section{PREVENTION}

The comprehension about patient characteristics is important to reduce PJK and PJF postoperatively. The risk factors should be enough considered for preventing PJK and PJF. There are several strategies to minimize PJK and PJF. Soft tissue protections, choice of a valid level and instrumentation at the UIV, prophylactic rib fixation, vertebral cement augmentation, adequate selection material of rods and age-appropriate spinopelvic alignment goals are worth consideration.

The soft tissue should be carefully dissected. Preservation of the interspinous ligaments, supraspinous ligaments, supra-adjacent facets, and their capsules at the UIV are considered to ease off the risk of $\mathrm{PJK}$ and $\mathrm{PJF}^{3)}$. In the preparation for surgery, confirming the range of exposure to avoid overexposure and 
soft tissue damage could be a method to alleviate the risk of PJK and PJF.

A choice of appropriate UIV requires careful consideration. Neutral and stable vertebra were selected as the UIV for decrease the incidence of revision ${ }^{26}$. The UIV at T8 or lower increased the PJK and the UIV at proximal level could cause perioperative complications ${ }^{2,6,39,42)}$. Thoracic hyperkyphosis have been regarded as a risk factor of PJK and $\mathrm{PJF}^{25,26,30,33,47,49,51)}$. Fusion extension to the upper thoracic level in patients with thoracic hyperkyphosis is considered to decrease the risk of PJK and PJF.

Instrumentation has been shown to be related with $\mathrm{PJK}^{15,25,26}$. Pedicle screws make rigid constructs and have a chance of facet violation ${ }^{15}$. To avoid the injury of facet joint, various trials with hooks have been reported. Hassanzadeh et al. ${ }^{14)}$ reported that PJK did not occur in patients with transverse process hook and pedicle screws.

Hart et al. ${ }^{12}$ reported the prophylactic rib fixation without fusion at the UIV+1. Vertical expandable prosthetic titanium rib (VEPTR) hook inserted at the medial posterior portion of the UIV+1 ribs through two longitudinal incisions. Then the VEPTR hooks are connected by titanium rods.

The vertebral cement augmentation at the UIV or UIV +1 has been proposed to be an effective method to prevent PJK and $\mathrm{PJF}^{8,13,46)}$. Hart et al. ${ }^{13)}$ reasoned that prophylactic vertebral cement augmentation cranial to UIV is an effective method. They reported that the patients with vertebral cement augmentation had shown low incidence of PJF. Martin et al. ${ }^{32)}$ reported that patients with vertebral cement augmentation at UIV and UIV+1 had shown lower incidence of PJF than historical data. In another study, cement augmentation at UIV and UIV+1 reduced proximal junctional fractures and associated revision surgeries ${ }^{46}$. Kebaish et al..$^{19)}$ reported a cadaveric study that prophylactic vertebral cement augmentation at the UIV and UIV +1 reduced the risk of junctional fractures. However, cement augmentation at only the UIV showed no significant benefit for preventing proximal junctional fractures.

The spinopelvic parameters including SVA, thoracic kyphosis, LL, and PI must be analyzed ${ }^{41,49,51)}$. Schwab et al. ${ }^{43)}$ introduced the relations between LL and PI that they should be within $9^{\circ}$ range $\left(\mathrm{PI}=\mathrm{LL} \pm 9^{\circ}\right)$. Lafage et al. ${ }^{28)}$ have demonstrated that normal range of the spinopelvic alignment in older patients is greater than younger patients. The age of patient has an influence on the decision of spinopelvic alignment goals. The age-appropriate alignment goals may reduce the risk of overcorrection and occurrence of PJK and $\mathrm{PJF}^{35}$.

Several studies have been suggested that fusion of the sacrum can increase the incidence of PJK ${ }^{2,24,49}$. $\mathrm{L} 5$ as the lowest instrumented vertebra promote the degeneration of the $\mathrm{L} 5-\mathrm{S} 1$ disc and the incidence of revision operation. Thus, we generally perform fusion down to the sacrum for avoiding additional surgery ${ }^{27}$.

The PJK and PJF could occur more frequently in patients with osteoporosis or osteopenia. Several reports suggested that bisphosphonates inhibit fusion, whereas the teriparatide could be used to reinforce fusion ${ }^{36,37}$. Recent studies suggested that the use of $\mathrm{CoCr}$ rod and multiple rod construct can increase rod stiffness, strengthen the stability of the construct of the spinal column, prevent rod breakage and affect the occurrence and the time of PJK. The authors speculated that PJK may occur more frequently in $\mathrm{CoCr}$ systems than in Ti systems ${ }^{9,10)}$. They strongly suggested that precise and personalized selection of rod should be considered and stiff rod such as stainless steel or $\mathrm{CoCr}$ is not always the best. The authors concluded that stiff rod may prevent rod fractures or pseudarthrosis but can cause PJK more frequently.

\section{CONCLUSION}

The advance of implants, surgical skills and basic knowledge for spinal deformity has permitted long-level spinal instrumentation and fusion. The ability to perform aggressive global realignment of spinal deformities has also led to the discovery of new complications such as PJK and PJF. Although several studies have reported incidence and risk factors for PJK, conclusive factors to lead PJK/PJF and solutions for prevention of the complication remain unsolved. Continuous research on PJK and PJF should be proceeded in order to comprehend the pathophysiology of these complications.

\section{CONFLICT OF INTEREST}

No potential conflict of interest relevant to this article was reported.

\section{REFERENCES}

1. Annis P, Lawrence BD, Spiker WR, Zhang Y, Chen W, Daubs MD, et al: Predictive factors for acute proximal junctional failure after adult deformity surgery with upper instrumented vertebrae in the thoracolumbar spine. Evid Based Spine Care J 5:160-162, 2014

2. Bridwell KH, Lenke LG, Cho SK, Pahys JM, Zebala LP, Dorward IG, et al: Proximal junctional kyphosis in primary adult deformity surgery: evaluation of 20 degrees as a critical angle. Neurosurgery 72:899-906, 2013

3. Cammarata M, Aubin CÉ, Wang X, Mac-Thiong JM: Biomechanical risk factors for proximal junctional kyphosis: a detailed numerical analysis of surgical instrumentation variables. Spine (Phila Pa 1976) 39:E500-507, 2014

4. Cho SK, Shin JI, Kim YJ: Proximal junctional kyphosis following adult spinal deformity surgery. Eur Spine J 23:2726-2736, 2014

5. Denis F, Sun EC, Winter RB: Incidence and risk factors for proximal and distal junctional kyphosis following surgical treatment for Scheuermann kyphosis: minimum five-year follow-up. Spine (Phila Pa 1976) 34:E729-734, 2009

6. Fujimori T, Inoue S, Le H, Schairer WW, Berven SH, Tay BK, et al: Long fusion from sacrum to thoracic spine for adult spinal deformity with sagittal imbalance: upper versus lower thoracic spine as site of upper instrumented vertebra. Neurosurg Focus 36:E9, 2014

7. Glattes RC, Bridwell KH, Lenke LG, Kim YJ, Rinella A, Edwards C 2nd: Proximal junctional kyphosis in adult spinal deformity following long instrumented posterior spinal fusion: incidence, out- 
comes, and risk factor analysis. Spine (Phila Pa 1976) 30:16431649, 2005

8. Ha Y, Maruo K, Racine L, Schairer WW, Hu SS, Deviren V, et al: Proximal junctional kyphosis and clinical outcomes in adult spinal deformity surgery with fusion from the thoracic spine to the sacrum: a comparison of proximal and distal upper instrumented vertebrae. J Neurosurg Spine 19:360-369, 2013

9. Han S, Hyun SJ, Kim KJ, Jahng TA, Kim HJ: Comparative study between cobalt chrome and titanium alloy rods for multilevel spinal fusion: proximal junctional kyphosis more frequently occurred in patients having cobalt chrome rods. World Neurosurg 103:404409, 2017

10. Han S, Hyun SJ, Kim KJ, Jahng TA, Lee S, Rhim SC: Rod stiffness as a risk factor of proximal junctional kyphosis after adult spinal deformity surgery: comparative study between cobalt chrome multiple-rod constructs and titanium alloy two-rod constructs. Spine J 17:962-968, 2017

11. Hart R, McCarthy I, O'Brien M, Bess S, Line B, Adjei OB, et al: Identification of decision criteria for revision surgery among patients with proximal junctional failure after surgical treatment of spinal deformity. Spine (Phila Pa 1976) 38:E1223-1227, 2013

12. Hart RA, McCarthy I, Ames CP, Shaffrey CI, Hamilton DK, Hostin R: Proximal junctional kyphosis and proximal junctional failure. Neurosurg Clin N Am 24:213-218, 2013

13. Hart RA, Prendergast MA, Roberts WG, Nesbit GM, Barnwell SL: Proximal junctional acute collapse cranial to multi-level lumbar fusion: a cost analysis of prophylactic vertebral augmentation. Spine J 8:875-881, 2008

14. Hassanzadeh H, Gupta S, Jain A, El Dafrawy MH, Skolasky RL, Kebaish KM: Type of anchor at the proximal fusion level has a significant effect on the incidence of proximal junctional kyphosis and outcome in adults after long posterior spinal fusion. Spine Deform 1:299-305, 2013

15. Helgeson MD, Shah SA, Newton PO, Clements DH 3rd, Betz RR, Marks MC, et al: Evaluation of proximal junctional kyphosis in adolescent idiopathic scoliosis following pedicle screw, hook, or hybrid instrumentation. Spine (Phila Pa 1976) 35:177-181, 2010

16. Hostin R, McCarthy I, O’Brien M, Bess S, Line B, Boachie-Adjei $\mathrm{O}$, et al: Incidence, mode, and location of acute proximal junctional failures after surgical treatment of adult spinal deformity. Spine (Phila Pa 1976) 38:1008-1015, 2013

17. Hyun SJ, Kim YJ, Rhim SC: Patients with proximal junctional kyphosis after stopping at thoracolumbar junction have lower muscularity, fatty degeneration at the thoracolumbar area. Spine J 16:1095-1101, 2016

18. Hyun SJ, Rhim SC: Clinical outcomes and complications after pedicle subtraction osteotomy for fixed sagittal imbalance patients: a long-term follow-up data. J Korean Neurosurg Soc 47:95-101, 2010

19. Kebaish KM, Martin CT, O’Brien JR, LaMotta IE, Voros GD, Belkoff SM: Use of vertebroplasty to prevent proximal junctional fractures in adult deformity surgery: a biomechanical cadaveric study. Spine J 13:1897-1903, 2013

20. Kim HJ, Bridwell KH, Lenke LG, Park MS, Ahmad A, Song KS, et al: Proximal junctional kyphosis results in inferior SRS pain subscores in adult deformity patients. Spine (Phila Pa 1976) 38: 896-901, 2013

21. Kim HJ, Bridwell KH, Lenke LG, Park MS, Song KS, Piyaskulkaew
C, et al: Patients with proximal junctional kyphosis requiring revision surgery have higher postoperative lumbar lordosis and larger sagittal balance corrections. Spine (Phila Pa 1976) 39:E576-580, 2014

22. Kim HJ, Lenke LG, Shaffrey CI, Van Alstyne EM, Skelly AC: Proximal junctional kyphosis as a distinct form of adjacent segment pathology after spinal deformity surgery: a systematic review. Spine (Phila Pa 1976) 37(22 Suppl):S144-164, 2012

23. Kim HJ, Yagi M, Nyugen J, Cunningham ME, Boachie-Adjei O: Combined anterior-posterior surgery is the most important risk factor for developing proximal junctional kyphosis in idiopathic scoliosis. Clin Orthop Relat Res 470:1633-1639, 2012

24. Kim YJ, Bridwell KH, Lenke LG, Glattes CR, Rhim S, Cheh G: Proximal junctional kyphosis in adult spinal deformity after segmental posterior spinal instrumentation and fusion: minimum fiveyear follow-up. Spine (Phila Pa 1976) 33:2179-2184, 2008

25. Kim YJ, Bridwell KH, Lenke LG, Kim J, Cho SK: Proximal junctional kyphosis in adolescent idiopathic scoliosis following segmental posterior spinal instrumentation and fusion: minimum 5year follow-up. Spine (Phila Pa 1976) 30:2045-2050, 2005

26. Kim YJ, Lenke LG, Bridwell KH, Kim J, Cho SK, Cheh G, et al: Proximal junctional kyphosis in adolescent idiopathic scoliosis after 3 different types of posterior segmental spinal instrumentation and fusions: incidence and risk factor analysis of 410 cases. Spine (Phila Pa 1976) 32:2731-2738, 2007

27. Kuhns CA, Bridwell KH, Lenke LG, Amor C, Lehman RA, Buchowski JM, et al: Thoracolumbar deformity arthrodesis stopping at L5: fate of the L5-S1 disc, minimum 5-year follow-up. Spine (Phila $\mathrm{Pa}$ 1976) 32:2771-2776, 2007

28. Lafage R, Schwab F, Challier V, Henry JK, Gum J, Smith J, et al: Defining spino-pelvic alignment thresholds: should operative goals in adult spinal deformity surgery account for age? Spine (Phila Pa 1976) 41:62-68, 2016

29. Lau D, Clark AJ, Scheer JK, Daubs MD, Coe JD, Paonessa KJ, et al: Proximal junctional kyphosis and failure after spinal deformity surgery: a systematic review of the literature as a background to classification development. Spine (Phila Pa 1976) 39:20932102, 2014

30. Lee GA, Betz RR, Clements DH 3rd, Huss GK: Proximal kyphosis after posterior spinal fusion in patients with idiopathic scoliosis. Spine (Phila Pa 1976) 24:795-799, 1999

31. Lee JH, Kim JU, Jang JS, Lee SH: Analysis of the incidence and risk factors for the progression of proximal junctional kyphosis following surgical treatment for lumbar degenerative kyphosis: minimum 2-year follow-up. Br J Neurosurg 28:252-258, 2014

32. Martin CT, Skolasky RL, Mohamed AS, Kebaish KM: Preliminary results of the effect of prophylactic vertebroplasty on the incidence of proximal junctional complications after posterior spinal fusion to the low thoracic spine. Spine Deform 1:132-138, 2013

33. Maruo K, Ha Y, Inoue S, Samuel S, Okada E, Hu SS, et al: Predictive factors for proximal junctional kyphosis in long fusions to the sacrum in adult spinal deformity. Spine (Phila Pa 1976) 38: E1469-1476, 2013

34. Mendoza-Lattes S, Ries Z, Gao Y, Weinstein SL: Proximal junctional kyphosis in adult reconstructive spine surgery results from incomplete restoration of the lumbar lordosis relative to the magnitude of the thoracic kyphosis. Iowa Orthop J 31:199-206, 2011

35. Nguyen NL, Kong CY, Hart RA: Proximal junctional kyphosis 
and failure-diagnosis, prevention, and treatment. Curr Rev Musculoskelet Med 9:299-308, 2016

36. Ohtori S, Inoue G, Orita S, Yamauchi K, Eguchi Y, Ochiai N, et al: Comparison of teriparatide and bisphosphonate treatment to reduce pedicle screw loosening after lumbar spinal fusion surgery in postmenopausal women with osteoporosis from a bone quality perspective. Spine (Phila Pa 1976) 38:E487-492, 2013

37. Ohtori S, Inoue G, Orita S, Yamauchi K, Eguchi Y, Ochiai N, et al: Teriparatide accelerates lumbar posterolateral fusion in women with postmenopausal osteoporosis: prospective study. Spine (Phila Pa 1976) 37:E1464-1468, 2012

38. O'Leary PT, Bridwell KH, Lenke LG, Good CR, Pichelmann MA, Buchowski JM, et al: Risk factors and outcomes for catastrophic failures at the top of long pedicle screw constructs: a matched cohort analysis performed at a single center. Spine (Phila Pa 1976) 34:2134-2139, 2009

39. O'Shaughnessy BA, Bridwell KH, Lenke LG, Cho W, Baldus C, Chang MS, et al: Does a long-fusion "T3-sacrum" portend a worse outcome than a short-fusion "T10-sacrum" in primary surgery for adult scoliosis? Spine (Phila Pa 1976) 37:884-890, 2012

40. Park SJ, Lee CS, Chung SS, Lee JY, Kang SS, Park SH: Different risk factors of proximal junctional kyphosis and proximal junctional failure following long instrumented fusion to the sacrum for adult spinal deformity: survivorship analysis of 160 patients. Neurosurgery 80:279-286, 2017

41. Rose PS, Bridwell KH, Lenke LG, Cronen GA, Mulconrey DS, Buchowski JM, et al: Role of pelvic incidence, thoracic kyphosis, and patient factors on sagittal plane correction following pedicle subtraction osteotomy. Spine (Phila Pa 1976) 34:785-791, 2009

42. Scheer JK, Lafage V, Smith JS, Deviren V, Hostin R, McCarthy IM, et al: Maintenance of radiographic correction at 2 years following lumbar pedicle subtraction osteotomy is superior with upper thoracic compared with thoracolumbar junction upper instrumented vertebra. Eur Spine J 24 Suppl 1:S121-130, 2015

43. Schwab F, Lafage V, Patel A, Farcy JP: Sagittal plane considerations and the pelvis in the adult patient. Spine (Phila Pa 1976) 34:1828-
1833, 2009

44. Smith MW, Annis P, Lawrence BD, Daubs MD, Brodke DS: Early proximal junctional failure in patients with preoperative sagittal imbalance. Evid Based Spine Care J 4:163-164, 2013

45. Smith MW, Annis P, Lawrence BD, Daubs MD, Brodke DS, et al: Acute proximal junctional failure in patients with preoperative sagittal imbalance. Spine J 15:2142-2148, 2015

46. Theologis AA, Burch S: Prevention of acute proximal junctional fractures after long thoracolumbar posterior fusions for adult spinal deformity using 2-level cement augmentation at the upper instrumented vertebra and the vertebra 1 level proximal to the upper instrumented vertebra. Spine (Phila Pa 1976) 40:1516-1526, 2015

47. Wang J, Zhao Y, Shen B, Wang C, Li M: Risk factor analysis of proximal junctional kyphosis after posterior fusion in patients with idiopathic scoliosis. Injury 41:415-420, 2010

48. Watanabe K, Lenke LG, Bridwell KH, Kim YJ, Koester L, Hensley M: Proximal junctional vertebral fracture in adults after spinal deformity surgery using pedicle screw constructs: analysis of morphological features. Spine (Phila Pa 1976) 35:138-145, 2010

49. Yagi M, Akilah KB, Boachie-Adjei O: Incidence, risk factors and classification of proximal junctional kyphosis: surgical outcomes review of adult idiopathic scoliosis. Spine (Phila Pa 1976) 36:E6068, 2011

50. Yagi M, Fujita N, Tsuji O, Nagoshi N, Asazuma T, Ishii K, et al: Low bone-mineral density is a significant risk for proximal junctional failure after surgical correction of adult spinal deformity: a propensity score-matched analysis. Spine (Phila Pa 1976) 2017 Aug 1 [Epub]. https://doi.org/10.1097/BRS.0000000000002355.

51. Yagi M, King AB, Boachie-Adjei O: Incidence, risk factors, and natural course of proximal junctional kyphosis: surgical outcomes review of adult idiopathic scoliosis. Minimum 5 years of follow-up. Spine (Phila Pa 1976) 37:1479-1489, 2012

52. Yagi M, Rahm M, Gaines R, Maziad A, Ross T, Kim HJ, et al: Characterization and surgical outcomes of proximal junctional failure in surgically treated patients with adult spinal deformity. Spine (Phila Pa 1976) 39:E607-614, 2014 